\title{
5 Research Square

\section{Management of elderly traumatic ankle arthritis with Ilizarov External Fixation: A Retrospective Study}

\author{
Jun Li \\ West China Hospital of Sichuan University \\ Wenzhao Wang \\ West China Hospital of Sichuan University \\ Hai Yang \\ West China Hospital of Sichuan University \\ Bohua li \\ West China Hospital of Sichuan University \\ Mingxin Li \\ West China Hospital of Sichuan University \\ Lei Liu ( $\square$ liuinsistence@163.com) \\ West China Hospital of Sichuan University
}

\section{Research Article}

Keywords: Elderly traumatic ankle arthritis, arthrodesis, Ilizarov External Fixation, End-stage

Posted Date: August 3rd, 2021

DOI: https://doi.org/10.21203/rs.3.rs-757620/v2

License: (c) (i) This work is licensed under a Creative Commons Attribution 4.0 International License.

Read Full License 


\section{Abstract}

Objective To evaluate the clinical effect of llizarov external fixation and ankle arthrodesis in the treatment of elderly traumatic ankle arthritis.

Methods From June 2015 to August 2019, 72 patients with elderly traumatic ankle arthritis were treated with arthrodesis through llizarov external fixation technique in our institution, 38 cases were males and 34 cases were females, with an average of 65.4 years (ranging from 60 to 74). Conventional double-feet loading positive and lateral $\mathrm{X}$ ray films were taken before operation. Angle between the tibia anatomic axis and the line segment of inside and outside of talus vertex was measured to evaluate the degree of talipes varus and valgus. Functional assessments were performed using Foot and Ankle pain score of American Orthopedics Foot and Ankle Society(AOFAS) and Visual Analogue Scale(VAS) .

Results All of the patients acquired effective postoperative 18-49 months follow-up, with an average of 31.5 months. All ankles achieved bony fusion, the clinical healing time was 12.7 weeks on average(11 18 weeks). The AOFAS score was $45.36 \pm 6.43$ preoperatively and $80.25 \pm 9.16$ at 12 months post operation, with a statistically significant difference $(P<0.0001)$. The VAS score was $8.56 \pm 1.85$ on average preoperatively and $2.72 \pm 0.83$ at 12 months post operation, with a statistically significant difference $(P<0.0001)$. The angle of anatomical tibial shaft and the line segment of inside and outside of talus vertex on X-ray image was $101.93^{\circ} \pm 4.12^{\circ}$ preoperatively and $94.45^{\circ} \pm 2.37^{\circ}$ at 12 months post operation, with a statistically significant difference $(P<0.0001)$. The results of functional evaluation indicated that 44 patients(61.1\%) had excellent results, 18 (25\%) had good results, and $10(13.9 \%)$ had fair results.

Conclusion Satisfactory curative effect can be obtained through llizarov external fixation and ankle arthrodesis in the treatment of elderly traumatic ankle arthritis.

\section{Introduction}

Traumatic ankle osteoarthritis is a degenerative disease caused by trauma, characterizing by a series of pathological changes including ankle joint cartilage degeneration, intra-articular inflammation, secondary hyperplasia and ossification[1]. In recent years, with the aging of the society and the extension of the life span of the population, the research on the prevention and treatment of degenerative diseases in elderly patients has become a multidisciplinary and active research topic. When elderly traumatic ankle arthritis does occur, it brings about disadvantages to routine activities and quality of life, such as pain and activity restriction[2]. Epidemiological studies[3] have shown that the causes of ankle joint osteoarthritis incorporating peripheral fractures of ankle(62\%), ligament injury (16\%), secondary reasons(13\%) such as rheumatoid arthritis, hemophilia and osteonecrosis, as well as the primary lesions (9\%). Comparing with other lower limbs arthritis, the ankle osteoarthritis arises at younger age and progresses faster, developing into end-stage within 10-20 years after the initial injury[4]. 
Although the implant materials are experiencing continuous development, total ankle arthroplasty is still limited to patients with low activity requirements, or patients with light weight, appproximately normal bony structure, and fair bone and soft tissue condition[5]. Ankle arthrodesis is deemed as the gold standard in the management of end-stage ankle arthritis. As a limb-sparing operation, ankle arthrodesis is a crucial alternative in patients with severe ankle pathologic conditions that may warrant a below-knee amputation[6]. Despite various techniques having been applied in the attempt to attain ankle arthrodesis, it is frequently associated with comorbidities including hindfoot arthritis, delayed or nonunions, tibial stress fractures, infection, and compromised wound healing, which can subsequently result in prolonged period of hospitalization and rehabilitation[7, 8].

The application of circumferential fixation for ankle arthrodesis was first introduced by llizarov[9]. The rationale of using Ilizarov circular frame is to provide dynamic axial compression and fixed angle stable fixation, a percutaneous technique that is fairly helpful in case of chronic deformity and poor skin conditions, and avoid using internal fixation materials in case of infection. The llizarov method has been proved to be useful in many complicated cases and contributes a favorable effect on improving the patients' quality of life[10,11]. However, reports about the effects of arthrodesis through llizarov external fixation on elderly traumatic ankle arthritis are still lacking. Thus the present study was aimed to retrospectively analyze the data on arthrodesis through llizarov external fixation in the treatment of elderly traumatic ankle arthritis in our institution, and try to: (1) evaluate the effect of llizarov external fixation on pain relieving, deformity correction, and function improvement; (2) summarize the complications and prevention measures, providing a reference for future use of ankle arthrodesis through llizarov external fixation.

\section{Patients And Methods}

Patient's characteristics

June 2013 to August 2019, 72 patients with elderly traumatic ankle arthritis were treated with arthrodesis through llizarov external fixation technique in our institution, among which 38 cases were males and 34 cases were females, with an average of 65.4 years(ranging from 60 to 74). 33 cases were on the left side, 39 cases were on the right side. All these patients were treated with conservative treatment for at least 6 months yet turned out to be invalid, with an average duration of 11.5 years (ranging from 6 to 38 years). Conventional double-feet loading positive and lateral $X$ ray films were taken before operation. Angle between the tibia anatomic axis and the line segment of inside and outside of talus vertex was measured to evaluate the degree of talipes varus and valgus. Functional assessments were performed using Foot and Ankle pain score of American Orthopedics Foot and Ankle Society(AOFAS) and Visual Analogue Scale (VAS). This retrospective study was conducted at the Department of Orthopedic Surgery at West China Hospital, Sichuan University and was approved by the internal research administration department and ethical committee. The medical records and radiographs of elderly patients traumatic ankle arthritis treated at our institution were reviewed by two orthopaedic surgeons who did not participate in the operation. 
After anesthesia, patient was set in horizontal position, with hip of affected side being blocked up. Through a $12 \mathrm{~cm}$ midline longitudinal incision in the anterior lower part of shank and along the talus, the skin, subcutaneous tissue, and the fascia were cut through layer by layer. The joint capsule was incised between the extensor hallucis longus tendon and the extensor digitorum longus tendon, the ankle was exposed (Fig. 1A), and the joint surface was cleaned. Articular cartilage and sclerous subchondral bone were debrided with osteotome, chisel, and curet until large amount of fresh blood oozed from the bone surface, then rinsed repeatedly with saline water (Fig. 1B). A $4 \times 3 \times 1 \mathrm{~cm}$ bone block was harvested using osteotome at the distal tibia (Fig. 1C), rinsed repeatedly with saline water, the bleeding was closed with bone wax. The llizarov circular frame was assembled according to the order of tibia, ankle and foot. After the rotation center of ankle being attached to the rotation center of external frame and shank being placed in the middle of the ring, a kirschner wire was pierced through the distal tibia. Two crossed kirschner wire were pierced through the middle and lower tibia to fix the proximal frame. After the rotation center being adjusted, a kirschner wire was pierced through middle lower section of 1-5 metatarsal from inside to outside. A kirschner wire was driven perpendicular to calcaneus from inside to outside to fix the supporting ring of foot. Two half wire were driven behind the calcaneus evading the achilles tendon and a kirschner wire was driven from the inside of first metatarsal (Fig. 1D). The detached cancellous bone was crushed and filled in the space of ankle joint, then covered with gelatin sponge. After being pressed, the external frame was fixed at $90^{\circ}$ position of ankle joint.

\section{Postoperative treatment}

Physical therapy, wound care and disinfection of pin tracts were regularly exerted after operation. The nuts of hinges were carefully adjusted when the local swelling of lower extremity subsided. The skin color, sensation, and tension of limbs were observed closely during the process of treatment. Patients were encouraged to take early weight-bearing walks with llizarov fixators, which were dismantled at three months on average.

\section{Functional evaluation}

Postoperative follow-up and physical examination were conducted by a senior clinical investigator of our group. Patients were inquired specifically about their overall experience with the external frames, restrictions of daily activities, real-time status of their ankle, complications and subsequent treatments. Imageological examination was carried out and angle between the tibia anatomic axis and the line segment of inside and outside of talus vertex was measured. Effectiveness of operation was evaluated using AOFAS scale and VAS scale. Functional recovery was divided into four classes: Excellent, no pain, limping or restrictions of daily activities, with X ray film confirmed bony fusion; Good, slight pain, occasional claudication and activity is slightly limited, with $\mathrm{X}$ ray film confirmed bony fusion; Fair, moderate pain, limping and activity limitations, with $\mathrm{X}$ ray film confirmed bony fusion; Poor, pain obviously, with failed bony fusion. 


\section{Statistical Analysis}

Statistical analyses were performed using Statistical Package for the Social Sciences (SPSS 19.0, IBM, NYC, USA). All data were expressed as the mean value \pm standard deviation (SD). The angle between the tibia anatomic axis and the line segment of inside and outside of talus vertex, AOFAS score and VAS score were compared by using paired $t$ test, in which a $P$ value of less than 0.05 was considered statistically significant.

\section{Results}

All of the patients acquired effective postoperative 18-49 months follow-up, with an average of 31.5 months. All ankles achieved bony fusion, the clinical healing time was 12.7 weeks on average(11 18 weeks). The AOFAS score was $45.36 \pm 6.43$ preoperatively and $80.25 \pm 9.16$ at 12 months post operation, with a statistically significant difference $(\mathrm{P}<0.0001)$. The VAS score was $8.56 \pm 1.85$ on average preoperatively and $2.72 \pm 0.83$ at 12 months post operation, with a statistically significant difference $(\mathrm{P}<0.0001)$. The angle of anatomical tibial shaft and the line segment of inside and outside of talus vertex on X-ray image was $101.93^{\circ} \pm 4.12^{\circ}$ preoperatively and $94.45^{\circ} \pm 2.37^{\circ}$ at 12 months post operation, with a statistically significant difference $(\mathrm{P}<0.0001)$. The results of functional evaluation indicated that 44 patients(61.1\%) had excellent results, 18 (25\%) had good results, and 10 (13.9\%) had fair results.

Table 1 Pre- and post- operation evaluation data.

\begin{tabular}{lcccc}
\hline & Pre-operation & post-operation & T Value & P value \\
\hline AOFAS score & $45.36 \pm 6.43$ & $80.25 \pm 9.16$ & 26.45 & $\mathrm{P}<0.0001$ \\
VAS score & $8.56 \pm 1.85$ & $2.73 \pm 0.87$ & 24.41 & $\mathrm{P}<0.0001$ \\
Angle of tibia-talus & $101.93^{\circ} \pm 4.12^{\circ}$ & $94.45^{\circ} \pm 2.37^{\circ}$ & 13.35 & $\mathrm{P}<0.0001$ \\
\hline
\end{tabular}

During the observation period, no continuous bleeding appeared in the incision area and pin tracts. Nine patients (12.5\%) developed slight pin tracts infection, all settled with local wound care and antibiotic treatment. In seven patients $(9.7 \%)$, the radiographs indicated anterior dislocation of talus, the problem was settled shortly by adjusting the structure of external fixator and tractive reduction. Five patients(6.94\%) appeared different degree of midfoot pain, which was solved by taking nonsteroidal anti-infammatory drugs(NSAIDs).

\section{Discussion}

Elderly traumatic ankle arthritis brings much inconvenience to patients' daily life, surgical treatment is usually demanding and difficult. There are more than forty surgery techniques reported in the literatures, ranging from intramedullary nail to screw fixation, plate-screw fixation, and external fixation technology[2, 
$6,12,13$ ]. Although internal fixation is currently the most widely applied strategy for ankle fusion, the role for other techniques of fixation and stabilization become increasingly apparent since complex ankle lesions increases. Both internal fixation and external fixation showed positive effects in obtaining reliable fixation, fusion and reducing infection $[14,15]$. The drawbacks and advantages of each fusion strategy should be taken into account in determining the course of treatment so as to acquire an optimal clinical effect[16].

With modular circular external fixator, the llizarov technique has demonstrated many advantages in ankle arthrodesis of complex cases, especially with comorbidities like bone defects, length discrepancies, distal tibia lesions, or the need for early ambulation with weight bearing, etc[17]. The characteristics of dynamic axial compression, and capacity to resist bending, torque and shearing enable the choice of early ambulation with weight bearing, which make it an ideal fixation instrument in the management of complex ankle lesions[18]. Unlike internal fixation, Ilizarov external fixation arthrodesis technology can be used in cases where bone and soft tissue conditions are poor, and can be used as first phase treatment in cases with active infection[19]. Continuous compression or distraction by the circular frame can provide excellent mechanical stability, which allows the surgeon to rectify the alignment and compress or distract during or after operation. This provides a more desirable choice for patients deemed improper for reliable screw fixation.

Another additional advantage of the llizarov technique for ankle arthrodesis is its capacity to equilibrate the length discrepancy of lower extremities via simultaneous tibial lengthening through distraction osteogenesis[20]. Distal tibia osteotomy in the process of ankle arthrodesis has also been demonstrated to be helpful in accelerating osseous fusion at the contact surface[21]. Apart from extremity lengthening, the theory of distraction osteogenesis can be applied to adjustment of malalignment[16, 22]. The capability to rectify the position and alignment of the forefoot and hindfoot by modulating the circular frame when needed in the course of regeneration is a distinct advantage of the llizarov technique[23]. Using these frames, any intraoperative errors can be addressed, early postoperative loss of position can be rectified, severe malalignment, septic arthritis, and failed fusion can be treated with a higher rate of success[24]. Hoover et al[25] compared conventional crossed-screw internal fixation to double ankle external fixation, the latter turn out to be more rigid constraints in both torsion and bending when compared to conventional crossed-screw technique. A biomechanical study by Thordarson et al proved that cancellous-bone screws provided better anti-rotation stress in human specimens with superior bone quality, whereas the external fixation demonstrated better anti- rotation stress in specimens with poorer bone quality[26]. Moreover, the screw fixation is basically invalid in osteopenic specimens. The llizarov technique is not without its drawbacks, which may include Kirschner wires breakage, incremental risk of superficial pin-track infections, likely discomfort caused by circular external fixator and so forth, with proper peri-operative care, especially proper post- operative nursing, these conditions can be reasonablely solved [22]. Our study indicated that fair results can be acquired in these settings.

If the patients are associated with comorbidities such as malignancy, major vascular disease, diabetes, chronic hypoxia, severe scarring, malnutrition, liver or kidney failure, chronic lymphedema, immune 
deficiency, or long-term smoking, ankle arthrodesis would be more challenging[7, 27]. Being hard for bony fusion, these patients used to have no choice but to take the non-operative therapy or amputation. Ilizarov external fixation technique has been used as the last limb salvage treatment for these complex cases and achieved satisfying effect[22, 28]. Kugan et al[29] reported 48 cases with multiple comorbidities and treated with llizarov external fixation technology, the ankle fusion rate was $83 \%$ and the patients' postoperative clinical function improved significantly, without recurrence of primary deep infection. Although a few foreseeable complications did exist, if recognized early and treated properly, they can be controlled, llizarov external fixation technology thus can be used as an effective alternative to amputation in such patients[30].

To sum up, the treatment of elderly traumatic ankle arthritis is still a challenging problem, comprehensive consideration should be made based on lesion degree of ankle joint and hindfoot, comorbidities, the general condition and relative risk factors. In addition, careful clinical and radiographic assessments are helpful in ensuring reasonable decision-making. Satisfactory curative effect can be obtained through Ilizarov external fixation and ankle arthrodesis in the treatment of elderly traumatic ankle arthritis.

\section{Declarations}

\section{Acknowledgements}

This study received funding from: the National Natural Science Fund of China (NO. 81874002); the Innovation and Entrepreneurship Project of Sichuan Technology Gallery (2020JDRC0054); the National Clinical Research Center for Geriatrics, West China Hospital, Sichuan University (Z20192013); China Postdoctoral Science Foundation (2021 M692279); West China hospital postdoctoral research and development fund(2019HXBH068).

Conflict of interest

The authors declare no conflict of interests.

\section{Author contributions}

Conceptualization, Writing-Review \& Editing, Jun Li; Data Analysis,Wenzhao Wang,Hai Yang; Data Curation, , Bohua li, Mingxin Li; Project Administration, Lei Liu.

\section{Availability of data and materials}

The datasets used for the current study are available from the corresponding author upon reasonable request.

\section{Ethics approval and consent to participate}

Ethics approval was obtained form the Institutional Review Boards of West China Hospital, Sichuan University. All the participants provided written informed consent. 


\section{References}

1. Saltzman CL, Hillis SL, Stolley MP, Anderson DD, Amendola A. Motion versus fixed distraction of the joint in the treatment of ankle osteoarthritis: a prospective randomized controlled trial. J Bone Joint Surg Am. 2012; 94: 961-970.

2. Delco ML, Kennedy JG, Bonassar LJ, Fortier LA. Post-traumatic osteoarthritis of the ankle: A distinct clinical entity requiring new research approaches. J Orthop Res. 2017; 35(3): 440-453.

3. Santos AL, Demange MK, Prado MP, Fernandes TD, Giglio PN, Hintermann B. Cartilage lesions and ankle osteoarthrosis: review of the literature and treatment algorithm. Rev Bras Ortop. 2014; 49: 565572.

4. Braito M, Dammerer D, Kaufmann G, Fischler S, Carollo J, Reinthaler A, et al. Are our expectations bigger than the results we achieve? a comparative study analysing potential advantages of ankle arthroplasty over arthrodesis. Int Orthop. 2014; 38: 1647-1653.

5. Kwon DG, Chung CY, Park MS, Sung KH, Kim TW, Lee KM. Arthroplasty versus arthrodesis for endstage ankle arthritis: decision analysis using Markov model. Int Orthop. 2011; 35: 1647-1653.

6. Gharehdaghi M, Rahimi H, Mousavian A. Anterior ankle arthrodesis with molded plate: technique and outcomes. Arch Bone Jt Surg. 2014; 2: 203-209.

7. Gorman TM, Beals TC, Nickisch F, Saltzman CL, Lyman M, Barg A. Hindfoot Arthrodesis with the Blade Plate: Increased Risk of Complications and Nonunion in a Complex Patient Population. Clin Orthop Relat Res. 2016; 474(10): 2280-99.

8. Wang C, Xu C, Li M, Li H, Wang L, Zhong D, et al. Arthroscopic ankle fusion only has a limited advantage over the open operation if osseous operation type is the same: a retrospective comparative study. J Orthop Surg Res. 2020; 15(1): 80.

9. Gubin AV, Borzunov DY, Marchenkova LO, Malkova TA, Smirnova IL. Contribution of G.A. llizarov to bone reconstruction: historical achievements and state of the art. Strategies Trauma Limb Reconstr. 2016; 11(3):145-152.

10. Illgner U, Budny T, Frohne I, Osada N, Siewe J, Wetz HH. Clinical benefit and improvement of activity level after reconstruction surgery of Charcot feet using external fixation: 24-months results of 292 feet. BMC Musculoskelet Disord. 2014; 15: 392.

11. Slater GL, Sayres SC, O'Malley MJ. Anterior ankle arthrodesis. World J Orthop. 2014; 5: 1-5.

12. Yasui Y, Hannon CP, Seow D, Kennedy JG. Ankle arthrodesis: A systematic approach and review of the literature. World J Orthop. 2016; 7: 700-708.

13. Popkov AV, Kononovich NA, Gorbach EN, Tverdokhlebov SI, Irianov YM, Popkov DA. Bone healing by using llizarov external fixation combined with flexible intramedullary nailing versus llizarov external fixation alone in the repair of tibial shaft fractures: experimental study. ScientificWorldJournal. 2014; 2014: 239791. 
14. Courville XF, Hecht PJ, Tosteson AN. Is total ankle arthroplasty a cost-effective alternative to ankle fusion? Clin Orthop Relat Res. 2011; 469: 1721-1727.

15. Li J, Li B, Zhang Z, Wang S, Liu L. Ilizarov external fixation versus plate internal fixation in the treatment of end-stage ankle arthritis: decision analysis of clinical parameters. Sci Rep. 2017; 7(1):16155.

16. Nguyen MP, Pedersen DR, Gao Y, Saltzman CL, Amendola A. Intermediate-term follow-up after ankle distraction for treatment of end-stage osteoarthritis. J Bone Joint Surg Am. 2015; 97: 590-596.

17. Fragomen AT, Borst E, Schachter L, Lyman S, Rozbruch SR. Complex ankle arthrodesis using the Ilizarov method yields high rate of fusion. Clin Orthop Relat Res. 2012; 470: 2864-2873.

18. Rodriguez-Collazo ER, Urso ML. Combined use of the llizarov method, concentrated bone marrow aspirate (CBMA), and platelet-rich plasma (PRP) to expedite healing of bimalleolar fractures. Strategies Trauma Limb Reconstr. 2015; 10: 161-166.

19. Kliushin NM, Sudnitsyn AS, Subramanyam KN, George J. Management of Neurologic Deformity of the Ankle and Foot With Concurrent Osteomyelitis With the llizarov Method. Foot Ankle Int. 2018; 39(2): 226-235.

20. Gaasbeek RD, Nicolaas L, Rijnberg WJ, van Loon CJ, van Kampen A. Correction accuracy and collateral laxity in open versus closed wedge high tibial osteotomy. A one-year randomised controlled study. Int Orthop. 2010; 34: 201-207.

21. Grivas TB, Magnissalis EA. The use of twin-ring llizarov external fixator constructs: application and biomechanical proof-of principle with possible clinical indications. J Orthop Surg Res. 2011; 6: 41.

22. Tellisi N, Fragomen AT, llizarov S, Rozbruch SR. Limb salvage reconstruction of the ankle with fusion and simultaneous tibial lengthening using the llizarov/Taylor spatial frame. HSS J. 2008; 4: 32-42.

23. Kliushin NM, Ababkov YV, Ermakov AM, Malkova TA. Modified Girdlestone arthroplasty and hip arthrodesis using the llizarov external fixator as a salvage method in the management of severely infected total hip replacement. Indian J Orthop. 2016; 50: 16-24.

24. Fragomen AT, Rozbruch SR. The mechanics of external fixation. HSS J. 2007; 3: 13-29.

25. Hoover JR, Santrock RD, James WR. Ankle fusion stability: a biomechanical comparison of external versus internal fixation. Orthopedics. 2011; 34(4).

26. Thordarson DB, Markolf K, Cracchiolo AR. Stability of an ankle arthrodesis fixed by cancellous-bone screws compared with that fixed by an external fixator. A biomechanical study. J Bone Joint Surg Am. 1992; 74: 1050-1055.

27. Saltzman CL, Kadoko RG, Suh JS. Treatment of isolated ankle osteoarthritis with arthrodesis or the total ankle replacement: a comparison of early outcomes. Clin Orthop Surg. 2010; 2: 1-7.

28. Ramos T, Ekholm C, Eriksson BI, Karlsson J, Nistor L. The llizarov external fixator-a useful alternative for the treatment of proximal tibial fractures. A prospective observational study of 30 consecutive patients. BMC Musculoskelet Disord. 2013; 14: 11. 
29. Kugan R, Aslam N, Bose D, McNally MA. Outcome of arthrodesis of the hindfoot as a salvage procedure for complex ankle pathology using the llizarov technique. Bone Joint J. 2013; 95-B: 371377.

30. Malizos KN, Gougoulias NE, Dailiana ZH, Rigopoulos N, Moraitis T. Relapsed clubfoot correction with soft-tissue release and selective application of Ilizarov technique. Strategies Trauma Limb Reconstr. 2008; 3: 109-117.

\section{Figures}
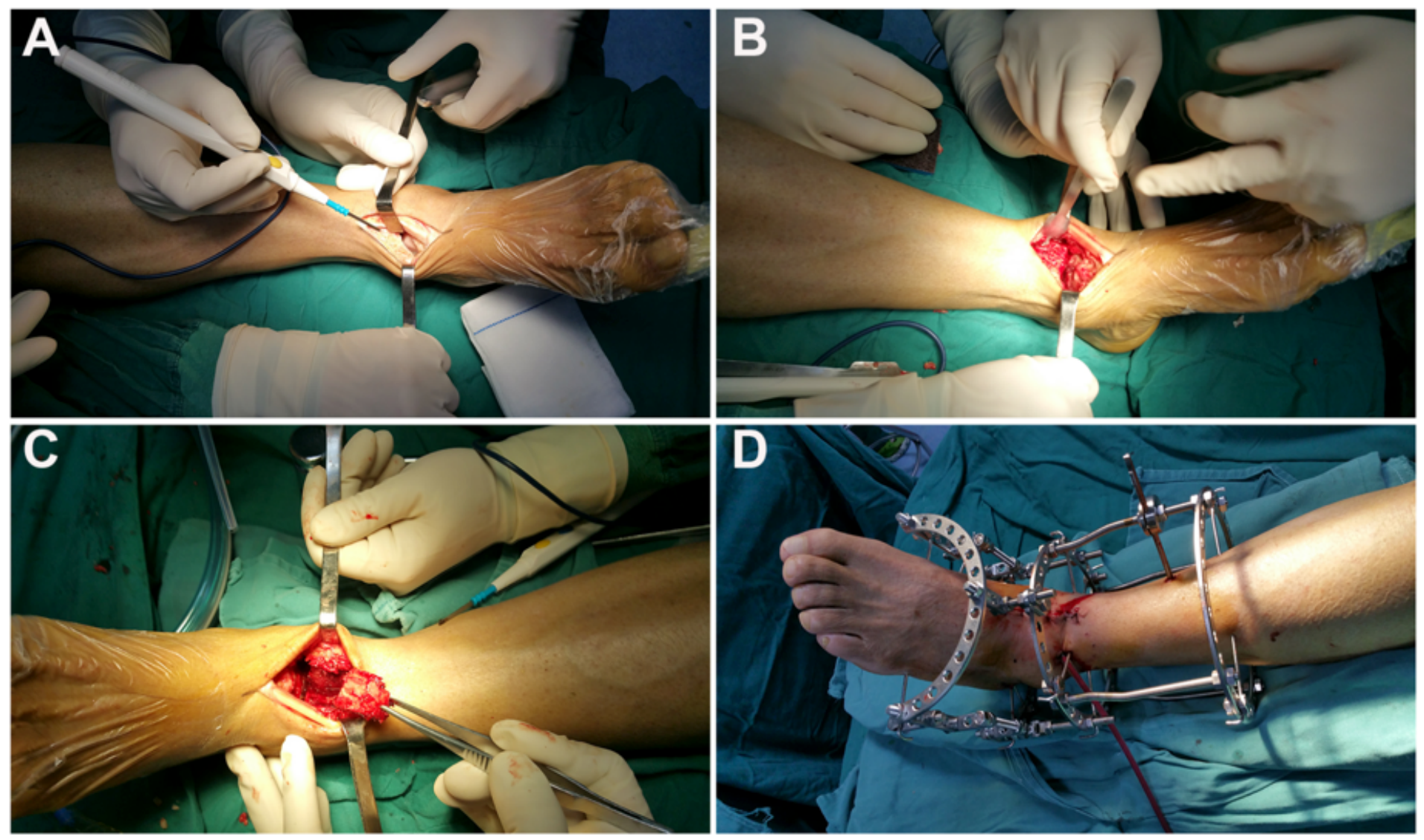

\section{Figure 1}

A, exposure of ankle; B, debridement of articular cartilage and sclerous subchondral bone; $\mathrm{C}$, harvest of cancellous bone; $D$, installation of llizarov external frame 

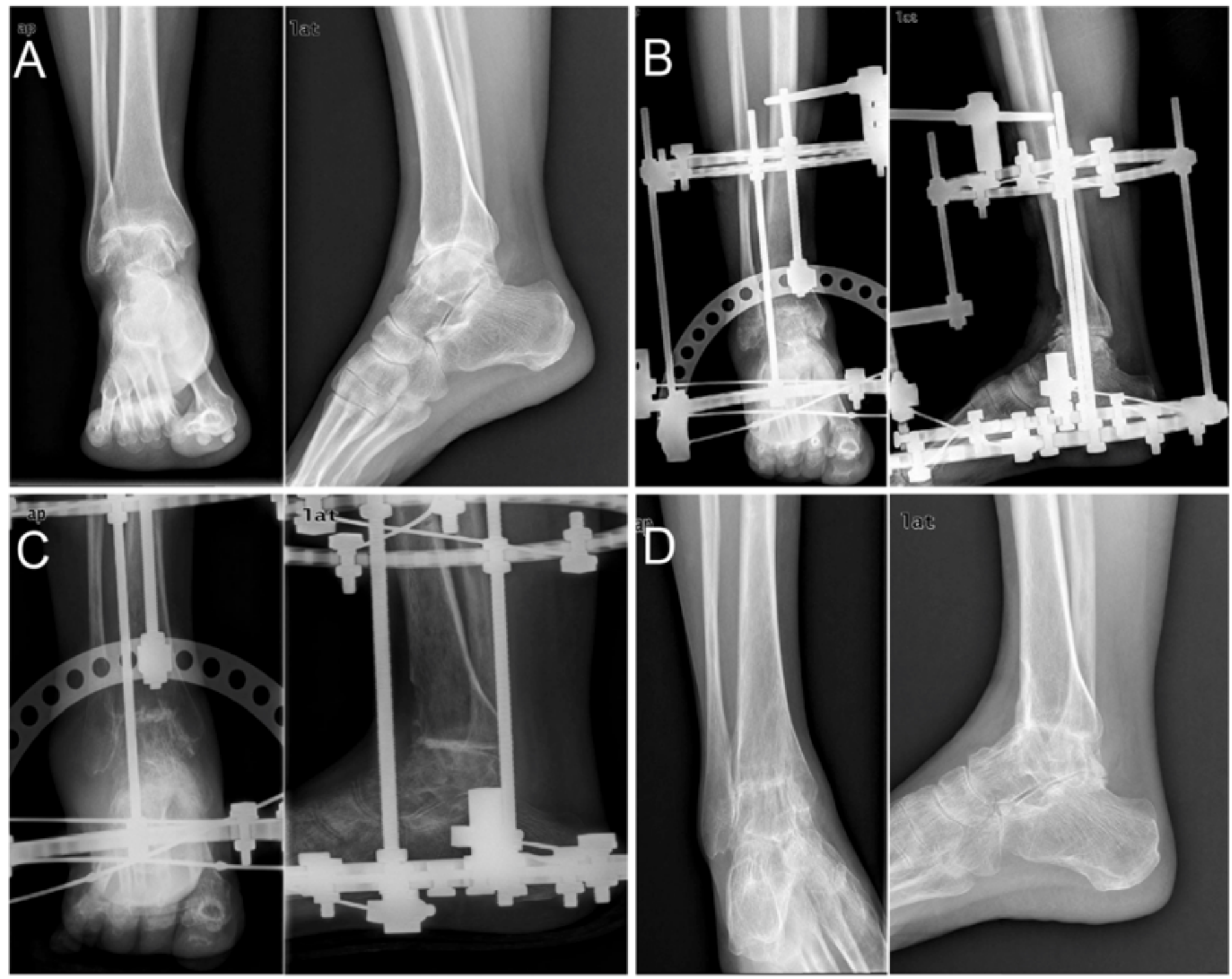

\section{Figure 2}

Typical case, female, 63 years old, pain after right ankle sprain for 10+ years. Diagnosis: Right ankle traumatic arthritis. A, preoperative anteroposterior and lateral X-ray films. B, post-operative anteroposterior and lateral X-ray films. C, anteroposterior and lateral X-ray films 6th months after operation. D, anteroposterior and lateral X-ray films 12th months after operation. 

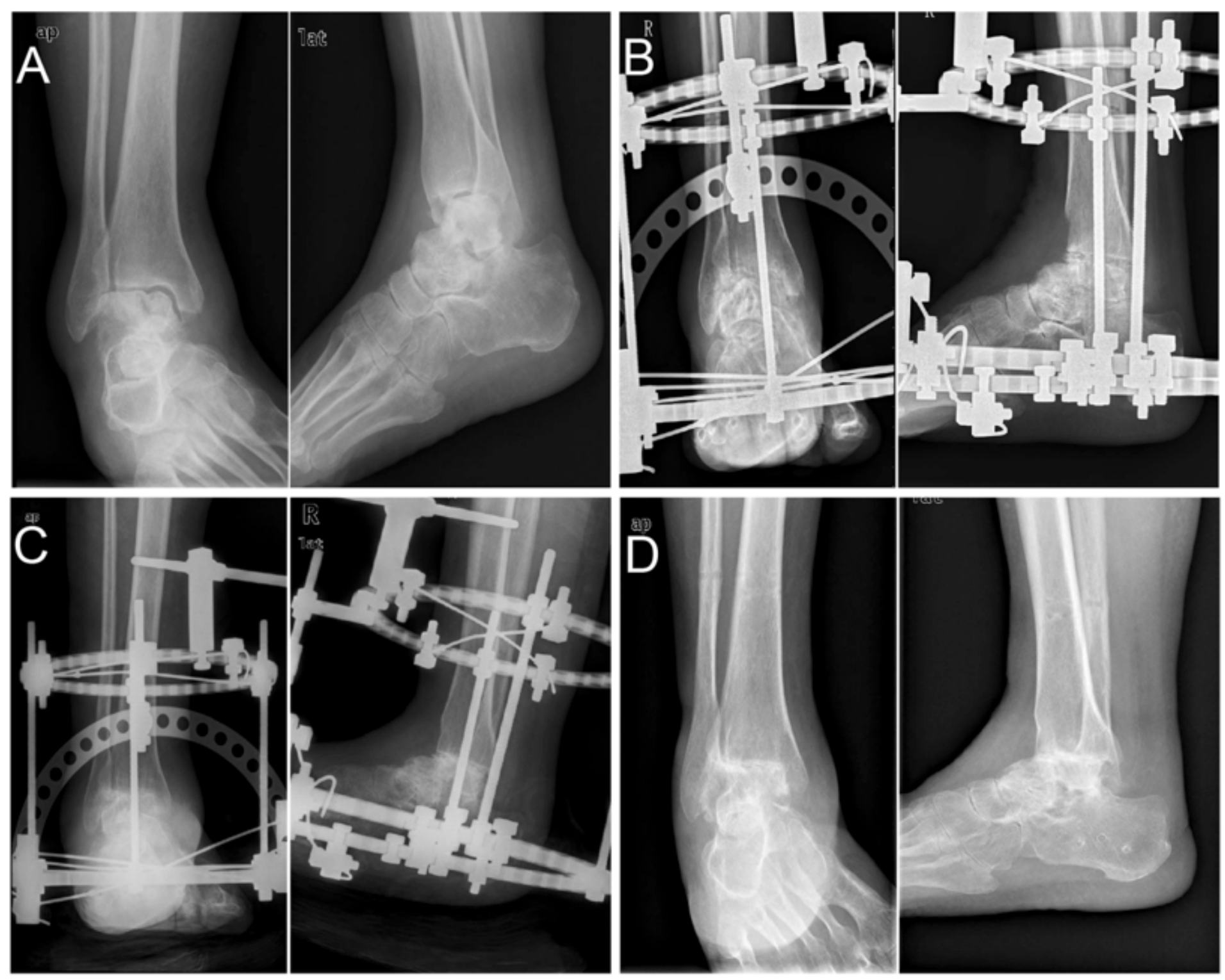

Figure 3

Typical case, female, 68 years old, trauma caused right talus fracture 1+ years after surgery, walking pain 10+ months. Diagnosis: Right ankle traumatic arthritis. A, preoperative anteroposterior and lateral X-ray films. B, postoperative anteroposterior and lateral X-ray films. C, anteroposterior and lateral X-ray films 6th months after operation. D, anteroposterior and lateral X-ray films 12th months after operation. 